\title{
THE APPLICATION OF MAGNESIUM ALLOYS IN AIRCRAFT INTERIORS - CHANGING THE RULES
}

\author{
Bruce Davis \\ Magnesium Elektron North America; 1001 College St. PO Box 258; Madison, IL, 62060, USA
}

\section{Extended Abstract}

The commercial aircraft market is forecast to steadily grow over the next two decades. Part of this growth is driven by the desire of airlines to replace older models in their fleet with newer, more fuel efficient designs, to realize lower operating costs and to address the rising cost of aviation fuel. As such the aircraft OEMs are beginning to set more and more demanding mass targets on their new platforms.

The cabin interior, including furnishings and operational items, account for $19 \%$ of the overall aircraft weight. This establishes it as a significant area for weight savings. Modern magnesium alloys can offer up to $30 \%$ mass reduction when directly replacing aluminum components, which makes them very attractive to designers and engineers. However, until recently, there have been restrictions on the use of magnesium in aircraft interiors that have been enforced through the SAE and the FAA.

The FAA has been working for the last seven years to assess the safety issues associated with the introduction of magnesium into the cabin interior. This work began with simplistic flammability testing of a wide range of alloys that identified different ignition behaviors of magnesium alloy types. This lead the FAA to undertake full scale fuselage staged burn tests of seat structures. The typical structural seat components are shown in Figure 1. The seats tested in the full-scale fuselage assessment contained five key parts fabricated from magnesium: spreader bars, seat leg assembly, cross tubes, baggage bars and the seat back frame.

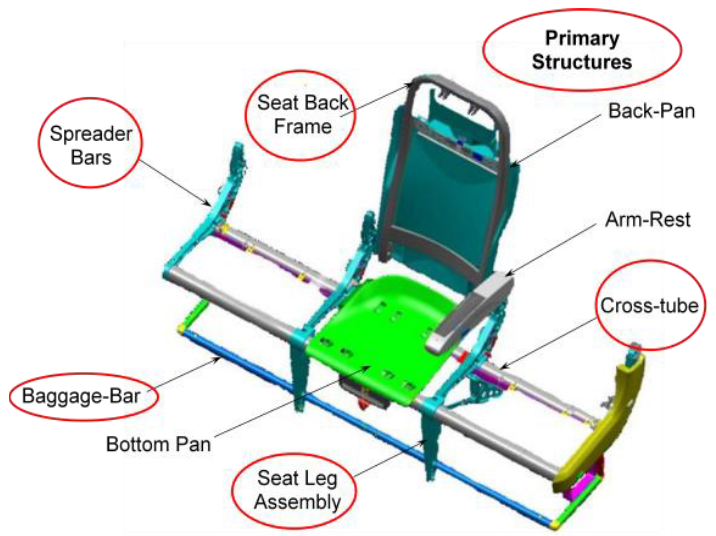

Figure 1. Schematic of major structural seat components

The testing arrangement is shown in Figure 2, which indicates the monitoring systems that were in place. The test assessed standard seat ignition properties compared to two magnesium containing seats containing either AZ31B alloy or Elektron ${ }^{\circledR} 43$.

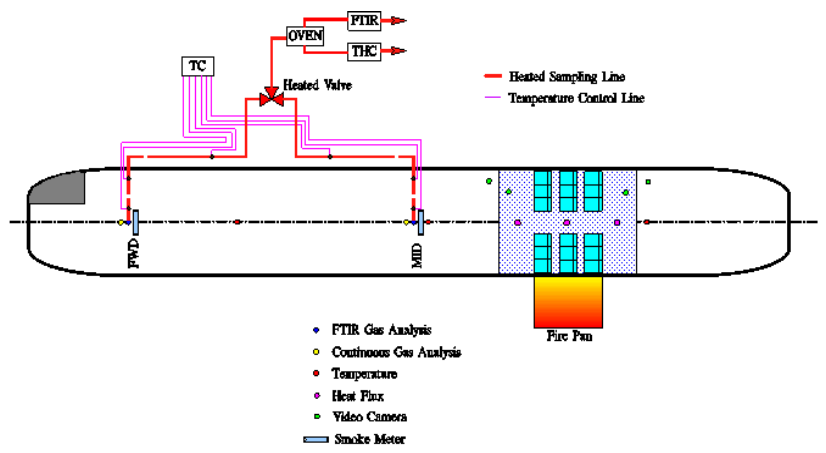

Figure 2. Overview of full-scale fuselage test.

The results of this testing showed that the presence of magnesium did not compromise passenger safety. The FAA has now issued guidelines on a laboratory scale flammability test. The test setup is shown in Figure 3. Magnesium alloys that meet the criteria of this test will be considered allowable for use in aircraft seat applications. The test method is available in the FAA's Aircraft Materials Fire Test Handbook Chapter 25 Oil Burner Flammability Test for Magnesium Alloy Seat Structure

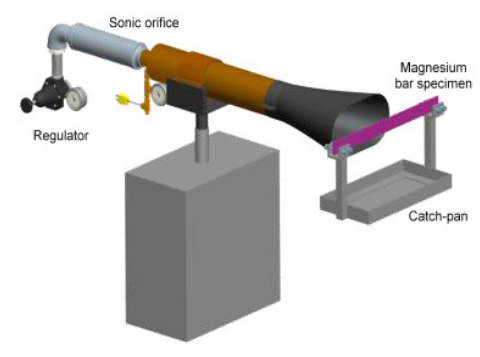

Figure 3. Lab scale burner test setup

The work by the FAA has culminated with a lifting of the ban of magnesium's application in aircraft seat applications. The FAA will now accept application for special conditions that will allow magnesium containing aircraft seat certification in commercial transport aircraft. Future work by the FAA will investigate methods of compliance (MOC) to allow magnesium in other aircraft interior applications, thereby extending the weight saving potential and benefit of today's advanced magnesium alloys.

Furthermore, the SAE standard AS8049 Rev B, which defines the engineering requirements of a commercial aircraft seat, restricts the use of magnesium in paragraph 3.3.3. AS8049 is currently undergoing its scheduled five year review. Revision $\mathrm{C}$ is scheduled to be issued in 2015 and paragraph 3.3.3 has been altered to allow the use of magnesium. The document now states that magnesium alloys maybe used in aircraft seats so long as the conform to the requirements set out in the Aircraft Materials Fire Test Handbook.

The application of the next generation magnesium alloys in aircraft interiors is now positioned to grow. 